\title{
Integrasi Pendidikan Matematika dan Pendidikan Islam (Menggagas Pembelajaran Matematika di Madrasah Ibtidaiyah)
}

\author{
M. Imamuddin ${ }^{1}$, Isnaniah ${ }^{2}, Z_{\text {Zulmuqim }}^{3}$, Syafruddin Nurdin ${ }^{4}$, Andryadi $^{5}$ \\ 1,2Institut Agama Islam Negeri (IAIN) Bukittinggi \\ 3,4Universitas Islam Negeri (UIN) Imam Bonjol Padang \\ 5Institut Agama Islam (IAI) Yasni Bungo, Jambi \\ 11m.imamuddin76@yahoo.co.id, 2iis_imam@yahoo.co.id \\ 3zulmuqim@uinib.ac.id, ${ }^{4}$ Syaf.nurd2in@gmail.com \\ 5Andryadi228@gmail.com
}

\begin{abstract}
Epistemologically, science and religion can be integrated, even must be integrated. Imam Suprayogo encourages science as an integration of religious values (Islam) with General Science or Science. The integration of Islamic Education and Mathematics Education in the learning proposed in this paper is Islamic education or Islamic values contained / presented/inherent in mathematics learning. Learning mathematics by incorporating Islamic values or teachings will help facilitate teachers in conveying mathematical concepts as well as Islamic education/Islamic values to students. This integrated mathematics learning is very compatible with the characteristics of Islamic schools/madrasah. Islamic values, help improve the formation of student character in accordance with the ideals of Islam and the nation.
\end{abstract}

Keywords: Integration, Islamic Education, Mathematics Education, Madrasah Ibtidaiyah

Abstrak: Berdasarkan epistemologis, sains dan agama bisa diintegrasikan, bahkan harus diintegrasikan. Imam Suprayogo mendefinisikan integrasi ilmu sebagai keterpaduan secara nyata antara nilai-nilai agama (Islam) dengan ilmu Pengetahuan Umum atau Sains. Integrasi pendidikan matematika dan pendidikan Islam dalam pembelajaran matematika dalam tulisan ini adalah pendidikan Islam atau nilai-nilai Islam yang tertuang/tersaji/melekat dalam pembelajaran matematika. Pembelajaran matematika dengan memasukkan nilai-nilai ataupun ajaran-ajaran Islam akan membantu mempermudah guru dalam menyampaikan konsep-konsep matematika dan sekaligus pendidikan Islam/nilai-nilai Islam kepada siswa. Pembelajaran matematika terintegrasi ini, sangat sesuai dengan karakteristik sekolah-sekolah Islam/madrasah. Pembiasaan penggunaan 
pembelajaran matematika terintegrasi dengan pendidikan Islam/nilai-nilai Islam, membantu mempercepat terbentuknya karakter siswa yang sesuai dengan cita-cita Islam dan bangsa.

Kata Kunci: Integrasi, Pendidikan Islam, Pendidikan Matematika, Madrasah Ibtidaiyah

\section{PENDAHULUAN}

Pendidikan unggul merupakan pendidikan yang diidam-idamkan oleh semua negara, termasuk Indonesia. Pendidikan ungggul, sebagaimana yang dikatakan Barbara G. Burch dalam Syafaruddin Nurdin yaitu "In Today's village educational excellence depend on our ability to not only contribute to the improvement of the world's economic but also educate all leaners to the fullest capacity", artinya "pendidikan yang mampu mengembangkan potensi dan kapasitas peserta didik secara optimal, sehingga yang bersangkutan mampu menghadapi dan memecahkan problema kehidupan yang dihadapinya sekaligus mampu mendukung pembangunan masa yang akan datang". ${ }^{1}$

Untuk itu, kurikulum 2013 dikembangkan atas dasar teori "pendidikan berdasarkan standar" (Standar-Based Education), dan teori kurikulum berbasis kompetensi. Kurikulum 2013 ini mengalami perubahan pada elemen berikut: (1) standar kompetensi kelulusan, (2) standar proses, (3) standar isi, dan (4) standar penilaian.

Sementara pada pendekatan pembelajaran, kompetensi dikembangkan melalui pendekatan pembelajaran tematik integratif dalam semua mata pelajaran. ${ }^{2}$ Oleh karena itu, pembelajaran terintegrasi (terpadu) sebenarnya memiliki basis yang jelas dalam pendidikan nasional. Dalam konteks ini, Sekolah-sekolah Islam atau madrasah memiliki keleluasaan berkreativitas dalam melakukan pembelajaran sains yang terintegrasi dengan agama.

Berdasarkan epistemologis, sains dan agama bisa diintegrasikan, bahkan harus diintegrasikan. Dalam perspektif epistemologi ilmu dalam Islam, antara Islam dan sains adalah satu entitas yang bersifat komplementer dan interdependensi. Pakar-pakar pendidikan Islam menyebut kedua entitas ini sebagai ayat-ayat Allah. Islam adalah ayat qauliyah (wahyu), sedangkan sains adalah ayat kauniyah (ciptaan/alam semesta). Oleh karena kedua ayat ini bersumber dari Allah, maka kedua-duanya berfungsi menjelaskan Kemahabesaran Allah. ${ }^{3}$

1Syafruddin Nurdin, Penerapan Model Pendekatan Aptitude-Trreatment Interaction (ATT) dalam Pembelajaran IPS Di SD, Disertai Doktor Ilmu Pendidikan, (Bandung: Program Pascasarjana Universitas Pendidikan Indonesia, 2001), h. 1.

2 Abdul Majid, Pembelajaran Tematik Terpadu, Cet. Ke-2, (Bandung: PT Remaja Rosdakarya, 2014), h. 35-36.

3 Hasan Langgulung, "Integrasi Ilmu di PTAI", makalah pada Seminar Nasional Mahasiswa Tarbiyah se-Indonesia di Yogyakarta tahun1994. 
Tematik adalah sub kurikulum yang terintegrasi. ${ }^{4}$ Sementara model pembelajaran tematik merupakan sub dari kurikulum integrasi yang dapat mengembangkan bermacam sains diantaranya adalah pembelajaran matematika dengan mengintegrasikan nilai-nilai pendidikan Islam secara terintegrasi dalam kurikulum sekolah.

Sekolah-sekolah Islam (Madrasah) di bawah Kementerian Agama secara ideal memilki peluang besar dalam menerapkan model pembelajaran terpadu (terintegrasi) antara matematika dan Islam. Sejak awal, ideal cita yang mendasari pendirian madrasah adalah upaya integrasi ilmu agama dan ilmu umum (baca: sains/ matematika). Secara historis sebagaimana ditunjukkan oleh Arief Subhan dalam risetnya munculnya madrasah sebagai lembaga pendidikan Islam di Indonesia merupakan hasil pertemuan budaya model pendidikan Belanda, modernisme pendidikan Islam, dan buadaya pendidikan pesantren. ${ }^{5}$ Sintesis ketiga faktor inilah kemudian yang memunculkan model kurikulum madrasah yang memilki semangat memadukan atau mengintegrasikan dan mengkoneksikan ilmuilmu keislaman dan ilmu-ilmu sekuler. ${ }^{6}$

Eksperimen madrasah sejak awal adalah upaya mengkombinasikan mata pelajaran keislaman dan pelajaran sekular dalam kurikulum. Berdasarkan Surat Kesepakatan Bersama (SKB) tiga menteri (Menteri Agama, Menteri Pendidikan dan Menteri Dalam Negeri) yang lebih dikenal dengan SKB Tiga Menteri (No. 6 Tahun 1975 dan No. 037/U/1975) sebagai payung hukum dalam memperbaiki dan penyempurnaan kurikulum dan kelembagaan madrasah. Pada SKB ini, yang dimaksud dengan madrasah adalah lembaga pendidikan yang menjadikan mata pelajaran agama Islam sebagai mata pelajaran dasar yang diberikan sekurangkurangnya 30 persen di samping mata pelajaran umum. ${ }^{7}$

Keluarnya SKB (Surat Keputusan Bersama) Tiga Menteri tahun 1975, menurut Mukti Ali (Menteri Agama masa itu) pada hakikatnya agar:

“... iklim belajar-mengajar di madrasah itu terbuka, tidak hanya belajar agama saja. Tetapi ada pelajaran Paspal, Ilmu Bumi, Sejarah, Matematika, dan pelajaran umum yang lain, yang semua buku pegangan dan standar penilainnya di bawah peraturan resmi pemerintah. Tidak dibiarkan liar. Itu saja. $L h a$, persoalan $70 \%$ dan $30 \%$ itu hanya adal dalam rumusan ide kita saja. Dalam praktiknya "kan bagaimana kedua jenis mata pelajaran itu saling

4 Robin Forgaty, The Mindful School Integrate The Curricula, (Ilions: IRI Skylight Training,2001), h. ix.

5 Arief Subhan, Lembaga Pendidikan Islam Indonesia Abad ke-20: Pergumulan antara Modernisasi dan Identitas, (Jakarta: Kencana, 2012), h. 211..

6 Arief Subhan, Lembaga Pendidikan Islam Indonesia Abad ke-20: Pergumulan antara Modernisasi dan Identitas, (Jakarta: Kencana, 2012), h. 251-252.

7 Arief Subhan, Lembaga Pendidikan Islam Indonesia Abad ke-20: Pergumulan antara Modernisasi dan Identitas, (Jakarta: Kencana, 2012), h. 254. 
mengisi. Itu juga yang oleh Pak Syarif Thayib (Menteri Pendidikan waktu itu) dan Pak Amir Machmud (Menteri dalam Negeri saat itu)".8

Berdasarkan penegasan Mukti Ali di atas, nampak jelas bahwa SKB tiga menteri itu secara tersurat memiliki semangat agar ilmu-ilmu keislaman yang menjadi core kurikulum madrasah saling mengisi dengan ilmu-ilmu umum (baca: sains/matematika). Dengan demikian, meskipun dalam praktiknya, kedua bidang ilmu ini berjalan sendiri-sendiri, namun output madrasah, secara kognitif telah memilki kompetensi keagamaan dan keilmuan (saintifik).

Undang-Undang Nomor 20 Tahun 2013 yang mengamanatkan bentuk kurikulum yang mengantarkan siswa mengembangkan potensinya menjadi manusia yang beriman dan bertakwa kepada Tuhan Yang Maha Esa, berakhlak mulia, sehat, berilmu, cakap, kreatif, mandiri, dan menjadi warga negara yang demokratis secara bertanggung jawab. ${ }^{9}$ Bambang Sudibyo (Menteri Pendidikan Nasional saat itu) menjelaskan bahwa keimanan dan ketakwaan serta akhlak mulia menjadi dasar pembentukan kepribadian peserta didik secara utuh. Kurikulum disusun sejauh mungkin agar matapelajaran dapat menunjang peningkatan iman dan takwa serta akhlak mulia. ${ }^{10}$

Berdasarkan penjelasan di atas, maka sekolah Islam atau madrasah telah mendapatkan keleluasaan yang bersifat idealistik, filisofis, sosiologis dan legalistik bagi cita-cita dan usaha pembelajaran sains/matematika yang terintegrasi dengan Islam. Jadi tujuan dalam penulisan artikel ini adalah untuk memberikan gambaran Integrasi Pendidikan Matematika dan Pendidikan Islam dalam Pembelajaran Matematika (pembelajaran tema) untuk Siswa Madrasah Ibtidaiyah.

\section{HASIL DAN PEMBAHASAN}

\section{Integrasi}

Dalam Kamus Besar Bahasa Indonesia Istilah integrasi mempunyai arti pembauran atau penyatuan dari unsur-unsur yang berbeda sehingga menjadi kesatuan yang utuh atau bulat. Secara harfiah integrasi berlawanan dengan perpisahan, suatu sikap yang meletakkan tiap-tiap bidang dalam kotak-kotak yang berlainan. ${ }^{11}$

Menurut Azyumardi Azra, integrasi adalah usaha untuk memadukan dan menggabungkan antara ayat Quraniyah dengan Kauniyah melalui sebuah kajian. ${ }^{12}$

8 Ali Munhanif, "Menuntaskan Integrasi Sistem Pendidikan, wawancara dengan Prof. Dr. Mukti Ali”, Madrasah, No. 03, Vol. 1 (April-Juni 1997), h. 36-41.

9 Undang-Undang Nomor 20 Tahun 2003 tentang Sistem Pendidikan Nasional, dalam Himpunan Peraturan di Bidang Pendidikan, Peny. Weinata Sairin, (Bandung: Yrama Widya, 2013), h. 4.

10 Bambang Sudibyo, "Mewrujudkan Pendidikan yang Menjawab Tantangan Zaman", dalam Himpunan Peraturan di idang Pandidikan, Peny. Weinata Sairin, (Bandung: Yrama Widya, 2013), h. viii.

11 Zainal Abiding Bagir, Integrasi Imu Dan Agama. (Bandung: Mizan Pustaka, 2010).

12 Zulmuqim, Integrasi Pendidkan Islam dan sains (Model Azyumardi Azra, M. Amin Abdullah dan Imam Suprayogo). Makalah disampaikan pada International Conference on Islamic 
Sejalan dengan itu, Imam Suprayogo mendefinisikan Integrasi Ilmu sebagai keterpaduan secara nyata antara nilai-nilai agama (dalam hal ini Islam) dengan ilmu Pengetahuan Umum atau Sains. ${ }^{13}$ Sedangkan M. Amin Abdullah mengistilahkan integrasi dengan integrasi-interkoneksi, dan diartikan sebagai usaha memahami kompleksitas fenomena keilmuan yang dihadapi manusia, baik keilmuan agama, keilmuan sosial, humaniora, maupun kealaman (kauniyah), yang tidak dapat berdiri sendiri. ${ }^{14}$ Kemudian Habsah mendefinisikan integrasi pendidikan adalah pendidikan yang didasarkan pada tujuan dengan menghasilkan peserta didik dengan kepribadian yang seimbang dalam intelektual, emosional, fisik dan aspek kejiwaan/spiritual. ${ }^{15}$ Untuk mencapai tujuan ini, adalah dengan melakukan integrasi pengetahuan, nilai-nilai luhur atau ahlak dalam satu kesatuan pengajaran dan pembelajaran yang terintegrasi yang mencakup aspek skill, bahasa, budaya dan spiritual.

Berdasarkan dari beberapa definisi di atas, maka integrasi diartikan sebagai upaya meleburkan atau pembauran dua ilmu yaitu ilmu agama dan ilmu umum (sain/matematika), sehingga tidak terjadi lagi pemisahan (dikotomi) ilmu yang selama ini menjadi bomerang bagi kemajuan ilmu itu sendiri. Dalam kontek tulisan ini, integrasi yang dimaksud adalah integrasi pendidikan matematika dan pendidikan Islam. Dua pendidikan ini menjadi satu yang saling menupangi atau menaungi sehingga betul-betul menjadi satu kesatuan yang utuh.

Dengan mengintegrasikan pendidikan matematika dan pendidikan Islam dalam kegiatan pembelajaran matematika akan dihasilkan peserta didik yang mempunyai kepribadian yang seimbang antara intelektual, emosional, skill, fisik, karakter dan spiritual.

\section{Pendidikan Islam}

Ahmad D. Marimba mengartikan Pendidikan Islam sebagai bimbingan yang ditujukan kepada jasmani dan rohani berdasarkan syariah Islam untuk terbentuknya kepribadian utama yang berdasarkan ajaran atau nilai-nilai Islam.

Education: Theme of Conference "Integrating Islamic Education and Sciences: Challenges For Future Hopes" FTIK Imam Bonjol Padang, 28-29 November 2019.

13 Zulmuqim, Integrasi Pendidkan Islam dan sains (Model azyumardi Azra, M. Amin Abdullah dan Imam Suprayogo). Makalah disampaikan pada International Conference on Islamic Education: Theme of Conference "Integrating Islamic Education and Sciences: Challenges For Future Hopes" FTIK Imam Bonjol Padang, 28-29 November 2019.

14 Zulmuqim, Integrasi Pendidkan Islam dan sains (Model azyumardi Azra, M. Amin Abdullah dan Imam Suprayogo). Makalah disampaikan pada International Conference on Islamic Education: Theme of Conference "Integrating Islamic Education and Sciences: Challenges For Future Hopes" FTIK Imam Bonjol Padang, 28-29 November 2019.

15 Ab. Halim Bin Tamuri dan Zetty Nurzuliana Rashed, The Role of Higher Learning Institutions In Itegrating Islamic Knowledge and Science In The Era of $21^{\text {st }}$ Century Education, Makalah disampaikan pada International Conference on Islamic Education: Theme of Conference "Integrating Islamic Education and Sciences: Challenges For Future Hopes" FTIK Imam Bonjol Padang, 28-29 November 2019, h. 4. 
Dengan pengertian lain seringkali beliau mengatakan maksud kepribadian utama diistilahkan kepribadian muslim, yaitu kepribadian yang memiliki nilai-nilai agama Islam. ${ }^{16}$ Selanjutnya Ashraf mendefenisikan pendidikan Islam adalah pendidikan yang melatih sensibilitas murid-murid sedemikian rupa, sehingga dalam perilaku mereka terhadap kehidupan, langkah-langkah dan keputusan begitu pula pendekatan mereka terhadap semua ilmu pengetahuan mereka diatur oleh etika nilainilai Islam yang sangat dalam dirasakan. ${ }^{17}$

Berdasarkan definisi di atas, maka pendidikan Islam merupakan sistem pendidikan yang mampu mendorong umat muslim untuk memimpin kehidupannya sesuai dengan ajaran Islam, karena ajaran atau nilai-nilai Islam telah menjiwai dan mewarnai corak kepribadiannya. Dengan kata lain, umat muslim yang telah mendapatkan pendidikan Islam itu harus mampu hidup di dalam kedamaian dan kesejahteraan sebagaimana yang diharapkan oleh cita-cita Islam. ${ }^{18}$

Sementara itu, ilmu pendidikan Islam merupakan pengetahuan yang mengajarkan bagaimana menjadi peserta didik yang baik yang sesuai dengan Alquran dan sunnah. ${ }^{19}$ Ilmu pendidikan Islam bukan hanya ilmu tentang pendidikan Islam, melainkan ilmu pendidikan yang Islami, yaitu uraian sistematis tentang ajaran Islam mengenai beberapa aspek dan komponen pendidikan. Jadi Ilmu pendidikan Islam adalah ilmu pendidikan yang Islami atau ilmu pendidikan dalam persepektif Islam. ${ }^{20}$

Peranan pendidikan Islam terhadap umat Islam merupakan salah satu manifestasi dari cita-cita hidup bersama untuk mewujudkan, melestarikan, mengalihkan dan menanamkan (internalisasi) dan mentransformasikan ajaranajaran atau nilai-nilai Islam kepada generasi ke generasi selanjutnya, sehingga nilainilai keagamaan/religious yang dicita-citakan umat Islam dapat berfungsi dan berkembang dalam masyarakat dari zaman ke zaman. Dengan demikian pendidikan Islam merupakan suatu sistem pendidikan yang mencakup seluruh aspek kehidupan yang dibutuhkan oleh hamba Allah, yang bersumber dari Alquran dan Al-hadits serta Ijtihad para Ulama muslim, untuk kepentingan duniawi dan ukhrawi. Oleh karena itu, semua cabang ilmu pengetahuan yang mengandung nilai manfaat dan maslahat merupakan ruang lingkup pendidikan Islam.

16 Nur Ubiyati, Ilmu Pendidikan Islam. (Bandung: Pustaka Setia, 1998), h. 5.

17 Ashraf, Ali, Horison Baru Pendidikan Islam. (Bndung: Pustaka Firdaus, 1996), h. 23.

18 Nur Ubiyati, Ilmu Pendidikan Islam. (Bandung: Pustaka Setia, 1999), h. 13.

19Imamuddin, M., Andryadi \& Zulmuqim, Islamic Education In The Al-Qur'an and Sunnah (Study About the Meaning of Education and Implication for Educator), Journal Educative: Journal of Educational Studies, 5 (1), 2020, h. 70-83

20 Abd. Chayyi Fanany, Ilmu Pendidikan Islam, (Surabaya: Taruna Media Pustaka, 2010), h.1. 


\section{Pendidikan Matematika}

Pendidikan adalah upaya sadar yang dilakukan agar peserta didik atau siswa dapat mencapai tujuan tertentu. ${ }^{21}$ Agar siswa dapat mencapai tujuan pendidikan yang telah ditentukan, maka diperlukan wahana yang dapat digambarkan sebagai kendaraan. Merujuk pada pengertian pendidikan tersebut, maka pembelajaran matematika adalah kegiatan pendidikan yang menggunakan matematika sebagai kendaraan untuk mencapai tujuan yang ditetapkan.

Dengan adanya kegiatan pendidikan, Guru matematika akan mampu menggunakan matematika untuk membawa siswa menuju tujuan yang ditetapkan, bila ia memahami dengan baik matematika yang akan digunakan sebagai wahana. ${ }^{22}$ Apabila pemahaman guru terhadap matematika kurang baik dapat dipastikan bahwa penggunaan matematika sebagai wahana pendidikan juga tidak akan berhasil seperti yang diharapkan. Hal itu dapat diibaratkan atau digambarkan sebagai seseorang yang akan membawa orang lain dengan sepeda (kendaraan) menuju suatu tempat tujuan, tetapi orang yang akan membawa itu tidak tahu liku liku tentang sepedanya. Apa akibatnya?

Matematika sebagai wahana pendidikan tidak hanya dapat digunakan untuk mencapai satu tujuan. Misalnya mencerdaskan siswa, tetapi dapat pula untuk membentuk kepribadian siswa serta mengembangkan keterampilan tertentu. Hal itu mengarahkan perhatian kepada pembelajaran nilai-nilai, akhlak dan spritual dalam kehidupam melalui matematika.

Bagaimana seorang guru berusaha menguasai matematika yang akan diajarkannya, serta bagaimana mengajarkannya kepada siswa yang tengah berkembang, merupakan seni atau kiat tersendiri. Tidaklah benar kalau ada anggapan bahwa seseorang yang telah menguasai matematika dengan baik, akan dengan sendirinya mampu mengajarkannya dengan baik pula. ${ }^{23}$ Mengajar membutuhkan kreativitas dari seorang guru. Semakin kreatif guru dalam melaksanakan pembelajaran, semakin banyak masalah-masalah pembelajaran yang dapat teratasi. Hal ini, sejalan dengan yang disampaikan Isnaniah, bahwa kretaivitas mampu menyelesaikan permasalah. ${ }^{24}$

21 R. Soedjadi, Kiat Pendidikan Matematika Di Indonesia: Konatanta Keadaan Masa Kini Menuju Harapan Masa Depan. (Jakarta: Direktorat Jenderal Pendidikan Tinggi Departemen Pendidikan Nasional, 1999/2000), h. 6.

22 R. Soedjadi, Kiat Pendidikan Matematika Di Indonesia: Konatanta Keadaan Masa Kini Menuju Harapan Masa Depan. (Jakarta: Direktorat Jenderal Pendidikan Tinggi Departemen Pendidikan Nasional, 1999/2000), h. 6.

23 R. Soedjadi, Kiat Pendidikan Matematika Di Indonesia: Konatanta Keadaan Masa Kini Menuju Harapan Masa Depan. (Jakarta: Direktorat Jenderal Pendidikan Tinggi Departemen Pendidikan Nasional, 1999/2000), h. 7.

24 Isnaniah, Peningkatkan Kreativitas dan Kemandirian Belajar Mahasiswa Melalui Model Pembelajaran Berbasis Proyek Pada Perkuliahan Media Pembelajaran Matematika, Suska Journal of Mathematics Education, Vol. 3, No. 2, 2017, h. 83- 91. 
Keabstrakan objek-objek matematika perlu diupayakan agar dapat diwujudkan secara lebih kontret, sehingga akan mempermudah siswa dalam mempelajari dan memahaminya. ${ }^{25}$ Selain itu, Siswa dapat menerapkan pemikiran dan pemodelan matematika untuk menyelesaikan masalah yang muncul pada disiplin ilmu lain. ${ }^{26}$ Karena dalam pembelajaran matematika dapat meningkatkan penalaran, daya piker rasional, efektif dan logis dalam mempelajari ilmu lainnya. ${ }^{27}$ Inilah kunci penting yang harus diketahui guru matematika, dan diharapkan dapat dijadikan pendorong untuk lebih kreatif dalam merencanakan pembelajaran, yang mustahil semua perencanaan pembelajaran dapat dibekalkan selama dalam pendidikan guru.

\section{Integrasi Pendidikan Matematika dan Pendidikan Islam Dalam Pembelajaran Matematika}

Integrasi pendidikan matematika dan pendidikan Islam dalam pembelajaran matematika disini maksudnya adalah pendidikan Islam atau nilai-nilai Islam yang tertuang atau tersaji atau melekat dalam pembelajaran matematika. Pembelajaran matematika dengan memasukkan pendidikan Islam atau nilai-nilai Islam atau ajaran-ajaran Islam akan membantu mempermudah guru dalam menyampaikan konsep-konsep matematika dan sekaligus pendidikan Islam/nilai-nilai Islam kepada siswa. Nur Indah sari, dkk., mengatakan salah satu mata pelajaran yang sarat akan makna Islami adalah matematika. ${ }^{28}$

Pembelajaran matematika yang dilakukan disekolah-sekolah dari tingkat dasar sampai perguruan tinggi hendaknya pembelajaran matematika yang sarat dengan nilai-nilai Islam atau karakter-karakter Islami. Hal ini, juga disimpulkan oleh Annisah kurniati, bahwa matematika perlu diperkenalkan dan diajarkan kepada anak sejak dini dan mengajarkan matematika sebaiknya ditambah dengan menanamkan ilmu keislaman, sikap terpuji dan akhlakul mahmudah. ${ }^{29}$

Pembelajaran matematika di sekolah-sekolah harus disesuaikan dengan tingkat perkemabangan siswa. Karena belajar matematika bagi para siswa khususnya siswa tingkat rendah atau dasar merupakan pembentukan pola pikir

25 Isnaniah dan M. Imamuddin, Students' Understanding of Mathematical Concepts Using Manipulative Learning Media in Elementary Schools, 1st Bukittinggi International Conference on Education, IOP Conf. Series: Journal of Physics: Conf. Series 1471 (2020) 012050 IOP Publishing.

26 M. Imamuddin, dkk., Kemampuan Koneksi Matematika Siswa Dengan Pendekatan Kontekstual Di SMPN 1 Banuhampu, Al-Khwarizmi: Jurnal Pendidikan Matematika dan Ilmu Pengetahuan Alam Maret 2019, Vol.7, No.1, h.11-22.

27 M. Imamuddin, dkk., Gender Based Perception on Understanding Mathematics Consep By Using PBL, Humanisme: Journal Of Gender studies, Vol. 03, No. 01, Januari - Juni 2019, h. 58-74.

28 Nur Indah Sari, Dkk., Matematika Dan Al-Quran Untuk Membentuk Pendidikan Berkarakter Islami, Prosiding Seminar Nasional Pendidikan Membangun Generasi Berpendidikan Dan Religius Menuju Indonesia Berkemajuan Seminar Nasional Pendidikan 2017, h. 334-338.

29 Annisah Kurniati, Mengenalkan Matematika Terintegrasi Islam Kepada Anak Sejak Dini, Suska Journal of Mathematics Education Vol.1, No.1, 2015, h. 1-8. 
dan karakter. Hal ini lah yang harus diperhatikan oleh para pendidik/guru/calon guru dalam mengelola pembelajaran matematika disekolah, dan disilah diperlukan kreatifitas seorang guru dalam mengelola pembelajaran, sehingga para siswa memahami matematika beserta karakteristiknya.

Pembelajaran matematika atau yang kita kenal saat ini dengan pembelajaran tema yang dilaksanakan di Madrasah Ibtidaiyah, pembelajaran tema yang terkait dengan matematika yang mengintegrasikan pendidikan Islam atau nilai-nilai Islam dapat dilakukan oleh para pendidik atau guru di dalam kelas-kelas matematika dengan banyak cara, misalnya ketika mengajar siswa tingkat dasar (kelas $3 \mathrm{MI} / \mathrm{SD}$ ) dalam mengajarkan materi pengurangan, guru harus mengajarkan konsep pengurang dengan memilih tema dan teknik-teknik penyelesaian yang Islami seperti contoh berikut:

Pak Abdussalam seorang peternak sapi, sapi ternaknya bejumlah 235 ekor. Pada hari Raya korban tahun 2020 ini, pak Abdussalam memberikan 28 ekor sapinya kepada pengurus masjid dan mushalla yang ada di sekitar kota Bukittinggi untuk dijadikan sapi korban. Berapa ekorkah jumlah sapi ternak pak Abdussalam sekarang?

Untuk menjawab soal cerita ini, guru hendaknya juga memilih cara penyelesaian yang syarat dengan nilai-nilai Islami. Seperti teknik memberi dan sama berikut ini:

\section{Teknik memberi dan sama (optimisation) ${ }^{30}$}

Misalkan $235-28=\ldots$ ?

Penyelesaian soal 235- 28, dapat dikerjakan dengan langkah sebagai berikut:

$\begin{array}{lll}\text { Langkah 1 } & \begin{array}{l}5 \text { dikurangi } 8 \text { tidak bisa } \\ \text { atau tidak cukup. }\end{array} & 235 \\ & \text { Maka } 8 \text { dibawa ke puluhan } & \\ & \text { terdekat } & \\ \text { Langkah 2 } & \begin{array}{l}\text { 8 diberi 2 menjadi 10 } \\ \text { Karena 8 sudah diberi 2, }\end{array} & \underline{235}+2=237 \\ & \text { maka 5 juga harus sama } & \\ \text { diberi 2 menjadi 7 } & \\ \text { Langkah 3 } & \text { Menghitung 237 dikurangi } & 237 \\ & \text { 30. } & \underline{30}- \\ & \text { Dari 237, diambil 30. } & 207 \\ & \text { Diperoleh 207 }\end{array}$

Pada pengerjaan 235 - 48 dengan teknik memberi dan sama (optimisation), siswa akan terbiasa dengan kata-kata atau istilah memberi dan sama.

30 Abdussakir, Internalisasi Nilai-Nilai Islami Dalam Pembelajaran Matematika Dengan Strategi Analogi, Makalah keynote speaker pada Seminar Nasional Integrasi Matematika dan Nilai Islami (SI MaNIS) 2017 oleh Jurusan Matematika FST UIN Maulana Malik Ibrahim Malang, Sabtu 6 Mei 2017. 
Membiasakan siswa dalam mengerjakan soal-soal pengurangan dengan teknik memberi dan sama akan berdampak positif kepada siswa. Secara tersirat, guru telah menanamkan nilai-nilai Islam. Hal ini diperkuat oleh Abdussakir, jika siswa senantiasa mendengar kalimat "memberi dan sama", maka secara tidak langsung guru telah mendidik siswa untuk menjadi dermawan dan adil. ${ }^{31}$

Selain dengan teknik memberi dan sama, siswa juga bisa diajarkan dengan teknik membantu. Pada teknik ini, yang cukup memberi bantuan kepada yang tidak cukup. Berbeda dengan yang selama ini guru ajarkan kepada siswa dikelaskelas matematika, dimana dalam pengurangan diajarkan yang tidak cukup meminjam atau meminta kepada yang cukup, hal yang demikian ini harus dihindari oleh guru. Dalam mengejakan soal pengurangan dengan teknik membantu, guru mengerjakan soal sebagai berikut:

Contoh:

\section{Teknik membantu ${ }^{32}$}

Misalkan $235-28=\ldots$ ?

Penyelesaian soal 235-28, dapat dikerjakan dengan langkah sebagai berikut:

$\begin{array}{lll}\text { Langkah 1 } & \begin{array}{l}5 \text { dikurangi } 8 \text { tidak bisa } \\ \text { atau tidak cukup. } \\ \text { Karena 3 mampu, maka 3 } \\ \text { memberi 1 (puluhan) ke 5 }\end{array} & 235 \\ \text { Langkah 2 } & \begin{array}{l}\text { Menulis 1 di dekat 5 dan } \\ \text { mencoret 3 lalu menulis 1. }\end{array} & 2 \frac{28}{1315}- \\ \text { Langkah 3 } & \begin{array}{l}\text { Menghitung } \\ \text { 15- } 8=7\end{array} & \frac{28}{207}- \\ & 2-2=0 & \\ & 2-0=2\end{array}$

Pada teknik membantu ini, tidak mengenal istilah "tidak cukup lalu meminjam". Nilai positif dari teknik ini adalah mengajarkan kepada siswa-siswa untuk memberi bantuan atau membantu kepada yang tidak berkecukupan sebelum yang tidak berkecukupan itu meminta atau meminjam kepada yang mampu. berikut:

Terkait memberi dan membantu ini, hadits Rasulullah SAW adalah sebagai

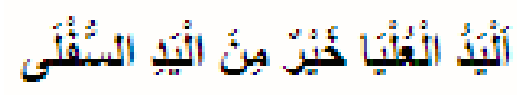

31 Abdussakir, Internalisasi Nilai-Nilai Islami Dalam Pembelajaran Matematika Dengan Strategi Analogi, Makalah keynote speaker pada Seminar Nasional Integrasi Matematika dan Nilai Islami (SI MaNIS) 2017 oleh Jurusan Matematika FST UIN Maulana Malik Ibrahim Malang, Sabtu 6 Mei 2017.

32 Abdussakir, Internalisasi Nilai-Nilai Islami Dalam Pembelajaran Matematika Dengan Strategi Analogi, Makalah keynote speaker pada Seminar Nasional Integrasi Matematika dan Nilai Islami (SI MaNIS) 2017 oleh Jurusan Matematika FST UIN Maulana Malik Ibrahim Malang, Sabtu 6 Mei 2017. 
Artinya: "Tangan di atas (memberi) lebih baik daripada tangan di bawah (meminta/menerima)"(HR. Bukhari: 1339).

Selain dalam teknik-teknik di atas, dalam menyampaikan materi matematika dalam pembelajaran tema. Pendidik atau guru dalam memberikan contoh soal, latihan soal bahkan dalam evaluasi dapat mengintegrasikan pendidikan Islam atau nilai-nilai keislaman dalam pembelajaran matematika (pembelajaran tema). Demikian juga, apabila guru memberikan bahan ajar kepada siswa, maka hendaknya di dalam bahan ajar itu tercermin nilai-nilai keislaman. Seperti yang disampaikan oleh Endah Wulantina, pengintegrasian pendidikan Islam atau nilainilai keislaman dalam buku ajar matematika setidaknya dapat tergambar dalam contoh-contoh soal, latihan mengerjakan soal dan soal-soal yang digunakan dalam mengevaluasi yang mengangkat masalah-masalah yang terjadi dalam perspektif Islam tanpa mengubah standar kompetensi yang terkandung dalam kurikulum yang telah ditetapkan. ${ }^{33}$

Bisa juga guru dalam pembelajaran tema atau pembelajaran matematika dalam memberikan contoh soal, latihan dan dalam memberikan evaluasi kepada siswa (siswa kelas VI MI/SD) untuk materi "Operasi pada Pecahan" dengan mengintegrasikan pendidikan Islam dalam pembelajaran matematika bisa seperti soal berikut: ${ }^{34}$

Contoh :

Aisyah A.F.I. adalah santriwati dari salah satu Pondok Pesantren yang ada di Madura. Setiap santriwati diwajibkan menyetor hafalannya setiap hari kepada wali asrama. Aisyah A.F.I. berusaha untuk menyelesaikan setoran surat 'Abasa selama 3 hari. Pada hari senin Aisyah A.F.I. menyetor $\frac{1}{3}$ dari banyak ayat surat 'Abasa. Selanjutnya pada hari selasa Aisyah A.F.I. menyetor kembali $\frac{1}{2}$ dari sisa setoran ayat sebelumnya. Banyak ayat yang belum disetor Aisyah A.F.I. untuk hari berikutnya adalah ...

Untuk mengerjakan soal di atas, terlebih dahulu siswa dituntut untuk mengetahui jumlah ayat pada surat Abasa. Setelah siswa mengetahui jumlah ayat pada surat Abasa, baru siswa bisa mengerjakan/menyelesaikan soal itu. Tanpa mengetahui jumlah ayat pada surat Abasa, siswa akan mendapatkan kesulitan dalam menyelesaikan soal itu. Dengan demikian, secara tidak langsung menuntun

33 Endah Wulantina, Pengembangan Bahan Ajar Matematika Yang Terintegrasi Nilai-Nilai Keislaman Pada Materi Garis Dan Sudut, Prosiding Seminar Nasional Matematika Dan Pendidikan Matematika UIN Raden Intan Lampung, tt, h. 367-373.

34 M. Imamuddin dan Hari Antoni Musril, Penembangan Soal-Soal Literasi Matematika Terintegrasi Dengan Al-Quran Di Mts N 2 Bukittinggi, Penelitian Interdisipliner BOPTN IAIN Bukittinggi 2019. 
siswa untuk mencari tahu jumlah ayat pada surat Abasa itu pada Al-quran atau Juz amma yang tersedia/ada di sekolah sebelum menyelesaikan soal. Dengan demikian secara tidak langsung siswa juga belajar Pendidikan Islam tanpa mengurangi tujuan dari pembelajaran matematika yang sudah ditetapkan.

\section{KESIMPULAN}

Pembelajaran matematika yang terintegrasi dengan Pendidikan Islam ataupun yang bermuatan nilai-nilai Islam, dapat membantu guru dalam menyampaikan konsep-konsep matematika dan sekaligus menanamkan konsepkonsep Islam/nilai-nilai Islam kepada siswa. Pembelajaran matematika terintegrasi dengan Pendidikan Islam ini, sangat sesuai dengan karakteristik dan mampu menunjang tercapainya dari visi-misi sekolah-sekolah Islam/ Madrasah. Karena dengan guru membiasakan penggunaan pembelajaran matematika yang terintegrasi dengan pendidikan Islam/nilai-nilai Islam, membantu mempercepat terbentuknya karakter siswa yang sesuai dengan cita-cita Islam dan bangsa. Dengan demikian, guru/pendidik selalu dituntut untuk berinovasi atau mengembangkan pembelajaran khususnya dalam menyelenggarakan pembelajaran matematika atau pembelajaran umum lainnya yang terintegrasi dengan pendidikan Islam/nilai-nilai Islam di Madrasah Ibtidaiyah.

\section{DAFTAR PUSTAKA}

Ab. Halim Bin Tamuri dan Zetty Nurzuliana Rashed, The Role of Higher Learning Institutions In Itegrating Islamic Knowledge and Science In The Era of $21^{\text {st }}$ Century Education, Makalah disampaikan pada International Conference on Islamic Education: Theme of Conference "Integrating Islamic Education and Sciences: Challenges For Future Hopes" FTIK Imam Bonjol Padang, 28-29 November 2019

Abd. Chayyi Fanany, Ilmu Pendidikan Islam, Surabaya: Taruna Media Pustaka, 2010 Abdul Majid, Pembelajaran Tematik Terpadu, Cet. Ke-2, Bandung: PT Remaja Rosdakarya, 2014

Abdussakir, Internalisasi Nilai-Nilai Islami Dalam Pembelajaran Matematika Dengan Strategi Analogi, Makalah keynote speaker pada Seminar Nasional Integrasi Matematika dan Nilai Islami (SI MaNIS) 2017 oleh Jurusan Matematika FST UIN Maulana Malik Ibrahim Malang, Sabtu 6 Mei 2017

Ali Munhanif, "Menuntaskan Integrasi Sistem Pendidikan, wawancara dengan Prof. Dr. Mukti Ali”, Madrasah, No. 03, Vol. 1, April-Juni 1997

Annisah Kurniati, Mengenalkan Matematika Terintegrasi Islam Kepada Anak Sejak Dini, Suska Journal of Mathematics Education Vol.1, No.1, 1-8, 2015, DOI: http://dx.doi.org/10.24014/sjme.v111.1326 
Arief Subhan, Lembaga Pendidikan Islam Indonesia Abad ke-20: Pergumulan antara Modernisasi dan Identitas, Jakarta: Kencana, 2012

Ashraf, Ali, Horison Baru Pendidikan Islam. Bandung: Pustaka Firdaus, 1996

Bambang Sudibyo, "Mewujudkan Pendidikan yang Menjawab Tantangan Zaman", dalam Himpunan Peraturan di idang Pandidikan, Peny. Weinata Sairin, Bandung: Yrama Widya, 2013

Endah Wulantina, Pengembangan Bahan Ajar Matematika Yang Terintegrasi Nilai-Nilai Keislaman Pada Materi Garis Dan Sudut, Prosiding Seminar Nasional Matematika Dan Pendidikan Matematika UIN Raden Intan Lampung, tt, 367-373

Hasan Langgulung, "Integrasi Ilmu di PTAI", makalah pada Seminar Nasional Mahasiswa Tarbiyah se-Indonesia di Yogyakarta tabun 1994.

Imamuddin, M., Andryadi \& Zulmuqim, Islamic Education In The Al-Qur'an and Sunnah (Study About the Meaning of Education and Implication for Educator), Journal Educative: Journal of Educational Studies, 5 (1), 70-83, 2020, DOI: $10.30983 /$ educative.v5i1.3055

Imamuddin, M., Isnaniah, Rusdi dan Pedinal, P., Gender Based Perception on Understanding Mathematics Consep By Using PBL, Humanisma: Journal Of Gender studies, Vol. 03, No. 01, 58-74, Januari - Juni 2019, DOI: $\underline{10.30983 / \text { humanisme.v3i1.1061 }}$

Isnaniah dan M. Imamuddin, Students' Understanding of Mathematical Concepts Using Manipulative Learning Media in Elementary Schools, 1st Bukittinggi International Conference on Education, IOP Conf. Series: Journal of Physics: Conf. Series 1471 (2020) 012050 IOP Publishing. doi:10.1088/17426596/1471/1/012050

Isnaniah, Peningkatkan Kreativitas dan Kemandirian Belajar Mahasiswa Melalui Model Pembelajaran Berbasis Proyek Pada Perkuliahan Media Pembelajaran Matematika, Suska Journal of Mathematics Education, Vol. 3, No. 2, 83-91, 2017

M. Imamuddin \& Hari Antoni Musril, Pengembangan Soal-Soal Literasi Matematika Terintegrasi Dengan Al-Quran Di Mts N 2 Bukittinggi, Penelitian Interdisipliner BOPTN IAIN Bukittinggi 2019

M. Imamuddin, dkk., Kemampuan Koneksi Matematika Siswa Dengan Pendekatan Kontekstual Di SMPN 1 Banuhampu, Al-Khwarizmi: Jurnal Pendidikan Matematika dan Ilmu Pengetabuan Alam, 7 (1), 11-22, 2019

Nur Indah Sari, Dkk., Matematika Dan Al-Quran Untuk Membentuk Pendidikan Berkarakter Islami, Prosiding Seminar Nasional Pendidikan Membangun 
Generasi Berpendidikan Dan Religius Menuju Indonesia Berkemajuan Seminar Nasional Pendidikan 2017

Nur Ubiyati, Imu Pendidikan Islam, Bandung: CV. Pustaka Setia, 1999

Nur Ubiyati. Ilmu Pendidikan Islam. Bandung: Pustaka Setia, 1998

R. Soedjadi, Kiat Pendidikan Matematika Di Indonesia: Konatanta Keadaan Masa Kini Menuju Harapan Masa Depan. Jakarta: Direktorat Jenderal Pendidikan Tinggi Departemen Pendidikan Nasional, 1999/2000

Robin Forgaty, The Mindful School Integrate The Curricula, Ilions: IRI Skylight Training, 2001

Syafruddin Nurdin, Penerapan Model Pendekatan Aptitude-Trreatment Interaction (ATT) dalam Pembelajaran IPS Di SD, Disertai Doktor Ilmu Pendidikan, Bandung: Program Pascasarjana Universitas Pendidikan Indonesia, 2001

Undang-Undang Nomor 20 Tahun 2003 tentang Sistem Pendidikan Nasional, dalam Himpunan Peraturan di Bidang Pendidikan, Peny. Weinata Sairin, Bandung: Yrama Widya, 2013

Zainal Abiding Bagir, Integrasi Imu Dan Agama. Bandung: Mizan Pustaka, 2010

Zulmuqim, Integrasi Pendidkan Islam dan Sains (Model Azyumardi Azra, M. Amin Abdullah dan Imam Suprayogo). Makalah disampaikan pada International Conference on Islamic Education: Theme of Conference "Integrating Islamic Education and Sciences: Challenges For Future Hopes” FTIK Imam Bonjol Padang, 28-29 November 2019 